\title{
DESIGN OF A WORKBENCH AND GUIDELINES TO IMPROVE THE EFFICACY OF ADVERTISING MESSAGES
}

\author{
Raffaella Folgieri \\ Tea Baldigara \\ Sergej Gricar
}

https://doi.org//10.20867/tosee.06.18

\begin{abstract}
Purpose - This study is aimed at proposing the design of an efficient workbench and guidelines to help content providers in tourism to address proper messages both in managing ordinary activities and in facing unpredictable events and external shocks.

Recent Covid-19 related events have particularly stressed the importance of tools supporting, guiding and directing message providers in designing advertising campaigns to attract visitors providing proper information and contrasting the possible negative influence of misinformation. Social media and the Internet can give a wide picture of current trends. Nevertheless, without appropriate tools suitable to analyse a huge quantity of data, the research of information on trends and mood by advertising providers constitutes a challenge difficult to face unless limited to the analysis of selected websites with consequent possible loss of details. Such a choice, based on humans' subjective selection of sources, could introduce bias compromising the efficiency of the message.

Methodology - Several studies state that the composition of an advertising campaign should be a conjoint activity including both creative and scientific work, involving also methodologies and tools helping messages provider to improve the efficacy and the impact of advertising campaigns. The present study aims to introduce an innovative methodology based on combining ideas from Information Technology and Econometrics. In particular Artificial Intelligence methods, such as Machine Learning and sentiment analysis, through the Artificial Neural Networks (ANN) and Vector Autoregressive models (VAR).

Findings - The language used and emotions elicited in tourism advertising messages have a strong impact on attracting visitors and tourists, particularly when international events create concerns in the population. Indeed, a multimodal approach, supported by tools from Econometrics, Machine Learning and Sentiment Analysis showed the efficacy in capturing the mood and the trend in prospect visitors to allow to redistribute tourist flows towards different destinations and within wider periods of the year.

Contribution - The work gives a theoretical and practical contribution. Indeed, the combination of Econometrics, Artificial Neural Networks and Sentiment Analysis tools can constitute a scientific base to analyse trends and to compose advertising texts, websites and campaigns taking into account the impact of unexpected events and maximising Linguistics suggestions to improve the efficiency of messages. Besides, the tools also allow suggesting guidelines of the features and the structure that should be always considered. Last but not least, these tools could be used to select the main topics arising on the web and social networks around current issues perceived by visitors, allowing the selection of a list of Q\&A practical indications which can be translated into effective virtual assistants particularly useful when the personnel is reduced due to unexpected events and constraints, as during Covid-19 periods.
\end{abstract}

Keywords: Tourism, Econometrics, Machine Learning, Sentiment Analysis, Workbench, Virtual Assistant. 
ToSEE - Tourism in Southern and Eastern Europe, Vol. 6, pp. 269-281, 2021.

R. Folgieri, T. Baldigara, S. Gricar: DESIGN OF A WORKBENCH AND GUIDELINES TO IMPROVE ...

\section{INTRODUCTION}

Recent Covid-19 related events have stressed the importance of media communication. The unknown and the uncertainty about the new virus have contributed to creating confusion with a direct fear-effect on people. The tourism sector particularly suffered and has to face the challenge of rebuilding an image driving people's confidence in the travelling and hospitality industry, painted - unfortunately - as the possible main spreader of the virus.

In this context, advertising should take into account the negative influence of misinformation and content providers need a new approach considering not only messages related to entertainment, comfort, local attractions, respect for environment and nature, but also contrasting unconscious fear and informing people about rules and contingent traveling organization.

The global nature of the pandemic generates a huge quantity of information and misinformation so that a large percentage of people tried to get informed on social media and searches on the Internet. Despite the Internet and social media constitute fast means to acquire fresh information about an event, in the pandemic period they allowed panic to spread faster than the COVID-19 outbreak. This fact had an immediate effect on traveling and tourism and needs to be faced through proper advertising messages aiming at restoring visitors' confidence in the hospitality industry.

Nevertheless, the huge quantity of data that can be collected on the Internet about trends and moods puts providers of advertising in a complex position when they have to choose how to filtering information and contrast misinformation, with the consequent possible loss of important details. Moreover, the choice based on solely humans' subjective selection of sources could introduce bias compromising the efficiency and the perceived reliability of the message.

This study aims to propose the design of a potential workbench and guidelines designed to improve the efficacy of advertising messages and to provide content managers with effective decision-making support instruments.

In the first paragraph, the literature review is given; in paragraph two the workbench and the guidelines are presented Finally, the conclusion presents the hypotheses for the further development of the workbench and further steps in creating an innovative efficient decision support tool.

\section{LITERATURE REVIEW}

The importance of advertising messages in orienting tourism has been largely pointed out in several works (McCabe 2010; Wu et al. 2008; Hamouda 2018).

Folgieri et al. and Mamula et al. (Folgieri et al. 2017; Mamula et al. 2019), proved the effectiveness of Artificial Neural Networks (ANN) as a tool in efficient tourist arrivals modeling and forecasting. The use of prediction tools represents, indeed, an opportunity 
ToSEE - Tourism in Southern and Eastern Europe, Vol. 6, pp. 269-281, 2021.

R. Folgieri, T. Baldigara, S. Gricar: DESIGN OF A WORKBENCH AND GUIDELINES TO IMPROVE ...

in developing tourist income by orienting policies and advertising messages in the early stage of a touristic season. Moreover, the authors showed that ANNs constitute powerful Decision Support and Pattern Discovery tools even more accurate than other methods, such as Linear Regression. Despite content managers' works appears to be a job related only to communication abilities, the study stressed the scientific nature of the activity demonstrating the need to collect objective data before the design of a touristic campaign. Tourism statistics in the past and the use of ANN allow understanding how to orient the advertising campaign to distribute the tourism income in different periods of the year. Moreover, the Internet provides a great opportunity to collect information about visitors' mood and interests and about contingent fears due to safety, terrorism, or - as we could see in recent periods - health issues. Given the importance of creating an efficient advertising campaign, Folgieri et al. (Folgieri et al. 2018), extended the model including data from sentiment analysis. Data collected on social networks allowed to further increase the prediction accuracy, taking into account also collective trends and factors due to unexpected events. Strong evidence of the importance of collecting the mood on social media is given by recent statistics on the number of people prioritising the Internet to search for information about the Covid-19 pandemic and travelling. Several works (Yu et al. 2020; Flores et al. 2021; Williams et al. 2020) showed that "Subjects had a higher propensity to research travel than actively pursue general news related to the coronavirus." (MacSween and Canziani 2021). In their study, MacSween and colleagues stressed that tourists mostly $(34,4 \%)$ used online resources to get information compared to printed travel magazines or other sources.

This study assumes that a workbench providing content managers of predictions (by ANN and econometrics models) and moods (by Sentiment Analysis tools) could be useful to fight misinformation spreading on the Internet, as pointed out by several studies (Cinelli et al. 2020; Williams et al. 2020).

In their work, Depoux and colleagues (Depoux et al. 2020) stress the disproportionate compared to the true public health need - the impact of media and public sentiment on discontinuing airline services and implementing travel restrictions. As the authors point out, social media - specifically Twitter - have a preeminent role in amplifying the intensity of general mood. This is why, following Depoux et al. (2020), content managers should take into account also the results of sentiment analysis to address messages to fight social media panic when unexpected events occur.

\section{THE WORKBENCH DESIGNING - THEORETICAL CONCEPTS AND PRACTICAL IMPLICATIONS}

The importance of tourism to the world economy on the one hand, and the growing influence of advertising messages on potential tourists on the other, promote the idea of researching in the field of tourism whether there is a direct impact of the Covid 19 pandemic on tourism demand. 
ToSEE - Tourism in Southern and Eastern Europe, Vol. 6, pp. 269-281, 2021.

R. Folgieri, T. Baldigara, S. Gricar: DESIGN OF A WORKBENCH AND GUIDELINES TO IMPROVE ...

\subsection{Aims and motivations}

The research aims to check if there is a significant view of Covid-19 patients on tourist arrivals and how the messages regarding travel could be obtained from the official websites. Nevertheless, in the changing world, there is a need for different approaches in tourism, therefore, the consideration in terms of conceptual information and dissemination is towards the potential tourists who are particularly sensitive due to the recent restrictions.

The motivation of the study is threefold, likely, the presentation of different aspects of the methodology in influencing tourism demand during the pandemic; the presentation of the working tool for sentiment analysis accompanied by the case study Slovenia, where the daily data for 2020 were collected.

\subsection{The workbench design}

Additionally, considering results from the previous studies (Folgieri et al. 2017; Folgieri et al. 2018; Mamula et al. 2019; Folgieri et al. 2016; Folgieri and Bait 2014) and the dependency of people from news and media, this study hypothesised the design of guidelines and tools supporting providers of messages to create advertising to attract visitors. This first step aims to provide a framework aimed to develop in further steps of an undergoing conjoint project. The final aim consists of providing indications to set tourism advertising and campaign based on proper information and contrasting possible negative influence of misinformation.

As discussed in the previous paragraphs, several studies state that the composition of an advertising campaign should be a creative and scientific work, involving also methodologies and tools helping messages providers to improve the efficacy and the impact of campaigns. To support the proper setup of a campaign and messages, a fivephase methodology is designed to provide approach suggestions and tools. The process should be split into three main steps: objectives definition; data collection; analysis; set up; test.

In the first phase - named objectives definition - content providers need to identify the aim of the advertising campaign, the platform(s) where the messages will be published and the target public. A proper definition of the aim should allow targeting the reference period for the data collection as discussed in the following point. Moreover, the identification of the platform will allow the definition of the language to use. In this case, content providers should remember essential points guiding the composition of the message:

- Images and videos are more effective than words.

- Words and sentences must be tailored to the platform. For example, messages on social media like Twitter or FaceBook should be short and appealing, whilst advertising on websites or magazines have to be related to a coordinated image and rich of information about the place, the history, the environment preservation, nature and should be linked to other resources on the Internet, to match users' need and 
ToSEE - Tourism in Southern and Eastern Europe, Vol. 6, pp. 269-281, 2021.

R. Folgieri, T. Baldigara, S. Gricar: DESIGN OF A WORKBENCH AND GUIDELINES TO IMPROVE ...

improve their positive experience. Possibly, also virtual and augmented reality tools could be included in the campaign. Last, but not least, the public appreciates the possibility to access easily to information, then $\mathrm{QR}$ codes linked to resources on the Internet or to download useful apps should also be provided. The general tone of the scripts should reflect a positive mood and contrast possibly recent unexpected events.

- Interactivity represents the best opportunity to improve users' experience. Inviting visitors to leave comments or sign in for a touristic community or share photos and experiences are some of the ways to involve users.

A suggestion to improve interactivity is to provide a real-time chat to ask for information or emergency issues. The chat can be realised both with the assistance of a call centre or through the realisation of a chatbot. A chatbot (also called a chatterbot or, more generally, virtual assistant) consists of an automatic system designed to provide information and answers to users' questions. Chatbots can be based on textual and/or on voice recognition inputs and they can be included on the website or social media in the form of text/voicebased chat or, also, showing animated avatars. Chatbots are designed to learn from visitors' questions and can be realised using specific programming languages - such as, for example, AIML (Artificial Intelligence Markup Language, an XML dialect designed to create natural language software agents) - or any other programming languages chosen by developers (the choice depending on specific purposes and adopted platforms). Virtual Assistants' aim consists of letting the user thinking to be interacting with a human, then the language used in answers need to be colloquial. Questions from users to which the chatbot has not been able to give a proper reply are normally collected in specific log files. The learning process can be based on manual or automatic feeding of the knowledge base by developers based on the users' logs. A more efficient approach consists of feeding the chatbot using Machine Learning Artificial Intelligence algorithms, such as NLP (Natural Language Processing) algorithms. Despite the development of such a Virtual Assistant requires greater economic effort in the setup phase of the campaign, it will be surely less expensive - in the long term - than a call centre. Moreover, the chatbot could be used in different contexts and campaigns, just adapting the domain of the knowledge base. The definition of the target public is also essential to guide the choice of the platform and the language to use. To accomplish this phase a simple checklist, that the providers should use to verify if they considered all the listed variables is proposed.

Data collection can be performed by accessing statistics related to the considered period as outlined by the previous phase. These data will be used to feed ANNs and the vector autoregression (VAR) model. Also, the platform(s) chosen in the previous phase should guide the definition of sources to select for the sentiment analysis, which could be magazines, websites, social media.

It is worth noting that past events prove future trends, so VAR econometrics is an important additional part of the scientific approach to advertising and dissemination to become familiar with the dispersion of the data. While previous analysis by Gricar and Baldigara (2019) highlighted the importance of tourism to the national economy, policymakers are recognised as relevant partners in tourism demand and its growth process. Therefore, some aspects during the pandemic are further developed in the current research accompanied by VAR to identify the recent shocks that could explain the recent downturn in tourism. VAR model is a recognised method that allows us to discover properties in the secondary 
ToSEE - Tourism in Southern and Eastern Europe, Vol. 6, pp. 269-281, 2021.

R. Folgieri, T. Baldigara, S. Gricar: DESIGN OF A WORKBENCH AND GUIDELINES TO IMPROVE ...

quantitative time-series data. It is the main econometrics tool to explore the ideas that are hidden but present. Overall, before the sentiment analysis, the proposal of secondary data collection and its calculation by the VAR model will be supported.

Once data are collected and the sources for sentiment analysis are selected, the content providers should proceed with the analysis phase. In the analysis phase, according to previous research results, the use of ANNs is proposed to analyse statistical data and sentiment analysis tools to obtain insight into the general advertising messages' mood. In the prototype model a generic backpropagation ANN model is proposed and any sentiment analysis tool that can be retrieved on the Internet. Further developments of the proposed methodology will be focused on designing and developing specific tools and data.

The outcome of the analysis phase and the previous checklist will allow content providers to set up the message and the campaign. In this phase, all the aspects related to users' experience and engagement have to be taken into consideration. Media, interactivity, language should be targeted based on the previous checklist and data analysis. The suggested methodology adopted in this phase consists of a checklist designed to verify if all the collected information has been fulfilled in the production of the advertising campaign. Of course, subjective bias could be introduced in this phase, because of the human nature of content providers, furthermore, a further step consisting of the test of the designed message will be proposed.

The test phase can be conducted both using the results of the opinions expressed by a panel of users chosen as representatives of the target public and using sentiment analysis tools to check the positivity of the message. In this way, both human and automatic verification will be performed.

In the test phase, the use of Cognitive tests to verify the emotional engagement of the public is also suggested. These tests can be realised through online questionnaires and they should be designed specifically for the current campaign. As a guideline, the authors wish to point out that the test should present not only questions on the content of the message but also questions based on emotions solicited by the campaign presenting both images and keywords to the participants.

The described approach has a multimodal nature because it takes into account econometrics considerations deriving from the statistical data analysed by ANNs and VAR; sociological and linguistic analysis performed through to the sentiment analysis on social media and other sources; and human insight is given by the panel of involved users; all technology-driven thanks to the use of the ICT and Machine Learning (Artificial Intelligence) described tools.

\section{FROM THEORY TO PRACTICE: THE SLOVENIAN CASE STUDY}

Considering the complexity and multidisciplinary nature of the studied topic, as mentioned in the introductory part, after identifying and defining the general phases and guidelines of the workbench tool, the consideration of Covid-19 and its impact on tourism will be studied. Therefore, the objective is to contrast the negative impact of the 
ToSEE - Tourism in Southern and Eastern Europe, Vol. 6, pp. 269-281, 2021.

R. Folgieri, T. Baldigara, S. Gricar: DESIGN OF A WORKBENCH AND GUIDELINES TO IMPROVE ...

pandemic and text the website to verify if the promotional messages are positive enough to attract visitors. Nevertheless, the descriptive analysis is conducted to give an overview of the Slovenian tourism market and its considerations, moreover, the pandemic year 2020 is taken into account. To get familiar with the data, the model VAR is considered before the sentiment analysis.

Slovenia is a country located at the intersection of the Alps, the Adriatic Sea and Pannonian Valey. It has a medium climate and the tourist destinations are ski resorts, spas, coastal tourism and city breaks. Neighbouring countries are Austria to the north, Italy to the east, Croatia to the south and Hungary to the east. Due to expanding Croatian tourism in the last decade, Slovenia suffers from an increase in tourist arrivals, partly due to transit travellers to Croatia and partly due to overwhelming tourist arrivals worldwide. Therefore, according to World Bank data (https://data.worldbank.org/indicator/ ST.INT.ARVL?locations= SI), Slovenian summary data on tourist arrivals amount to 4.7 million in 2019, 4.4 million in 2018, 3.9 million in 2017, 3.4 million in 2016 and 3 million in 2015. Looking at the Covid-19 Premium database of Statistical Office the Republic of Slovenia, the summary statistics show that the decline in tourist arrivals in 2020 is obvious and is 3.0 million, which is a regression from the 2015 average (https://pxweb.stat.si/SiStat/en/Podrocja/Index/155/turizem). Moreover, Slovenia probably suffered from Covid-19 in 2020 and the number of cases was 120,529 (https://github.com/sledilnik/data/blob/master/csv/stats.csv) with a population of 2.1 million. Moreover, the relationship between tourist arrivals and Covid-19 in Slovenia is attributed to higher domestic demand and lower foreign demand (https://ec.europa.eu/eurostat/web/products-eurostat-news/-/ddn-20210315-2).

The simplified VAR(7) analysis from daily 2020 data is:

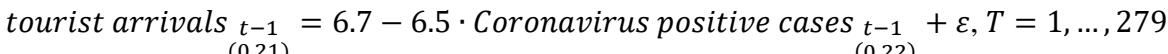
$(0.21) \quad(0.22)$

where the p-value of $t$-statistics is in parentheses and the Durbin-Watson -statistic is 2.00. The results show that there is no direct significant relationship between the number of infected individuals and tourist arrivals in Slovenia.

Nevertheless, the Covid 19 pandemic and tourism demand suffer from the decisions of policymakers, which are generally not limited to the impact on tourism. The decisions of policymakers were contrary to the general dissemination treatment, and therefore the information on websites is crucial for travellers and tourism demand. Overall, it can be concluded that tourism suffers only due to the European Union (EU) misguided policies regarding internal border crossing with the force of the EU treaty, e.g. Maastricht Treaty of 1992. In this sense, the sentiment analysis is conducted to check the dummies regarding these free movement treasures on the official Slovenian tourism websites. It is worth noting that according to Gričar (2019), only general viral diseases significantly affect tourism demand.

In this stage of our research, we designed the framework and a prototype of the Sentiment Analysis tool. Intending to test the model, we applied the guidelines and the prototype to the official guide to Slovenia (https://www.slovenia.info/en). 
ToSEE - Tourism in Southern and Eastern Europe, Vol. 6, pp. 269-281, 2021.

R. Folgieri, T. Baldigara, S. Gricar: DESIGN OF A WORKBENCH AND GUIDELINES TO IMPROVE ...

Following the steps of our framework, we first defined the objectives we wanted to achieve. Last, the designed checklist is to use as a guideline to verify if the website is balanced in light of the message and the target:

- Are there images on all the web pages of the website?

- Is there any video?

- Are the texts appealing and positive?

- Is the information clear and easy to access?

- Is the website well-organised?

- Is the website multilingual?

- Is the website interactive (allowing comments or share of photos or providing a community)?

- Is there any interactive virtual assistant to improve the users' experience?

- Is the website targeted to several types of tourists (per age range and typology)?

Regarding the list, the website resulted rich in images, with no video, appealing texts, clear and easy to access, well organised, multilingual, with low interactivity (it only allows to design a trip and to put places in a favourite list), without chatbot but providing traditional contacts, targeted to several types of visitors, per age-range and typology.

Apart from this visual analysis, we set up a panel of 10 people, equally distributed in sex and 5 range of age (under $16 ; 17-25 ; 26-35 ; 36-55$; over 55 ) and asked to express their opinion giving a score from 1 (low) and 5 (high).

The average among the scores deriving from the panel's opinions is shown in the following Table 1.

Table 1: Collected opinions (panel)

\begin{tabular}{lc}
\hline Question & Average Score \\
\hline Are there images on all the web pages of the website? & 5 \\
Is there any video? & 1 \\
Are the texts appealing and positive? & 4 \\
Is the information clear and easy to access? & 4 \\
Is the website well-organised? & 4 \\
$\begin{array}{l}\text { Is the website multilingual? } \\
\text { Is the website interactive (allowing comments or share of photos or } \\
\text { providing a community)? }\end{array}$ & 1 \\
$\begin{array}{l}\text { Is there any interactive virtual assistant to improve the users' } \\
\text { experience? }\end{array}$ & 1 \\
$\begin{array}{l}\text { Is the website targeted to several types of tourists (per age range and } \\
\text { typology)? }\end{array}$ & 4 \\
\hline
\end{tabular}


ToSEE - Tourism in Southern and Eastern Europe, Vol. 6, pp. 269-281, 2021.

R. Folgieri, T. Baldigara, S. Gricar: DESIGN OF A WORKBENCH AND GUIDELINES TO IMPROVE ...

The following step of the proposed framework consists of automatic analysis of the website content. As told, in this stage, a prototype to perform the Sentiment Analysis was developed and realized by NLP (Natural Language Processing) methods implemented in R platform.

The analysis showed that the website is globally positive, but with a very low value that is +0.561 . This means that the website results quite neutral and, then, there is room for improvement (especially in light of Covid-19 issues).

With the designed prototype tool, a concepts extraction was performed, aiming at detecting the main topics from the website's pages. The algorithms firstly examine titles and then, also based on the occurrence of most cited words, the quantity of text around each concept. Then, the NLP procedure evaluates the sentiment of the text related to the extracted concepts. Concepts can also include @handles and \#hashtags.

The concept extraction has been run in two steps: a first time to automatically detect concepts, as described; a second time to evaluate the sentiment. In this latter custom concepts to be evaluated were added. The evaluation goes from -10 to +10 , where the result around 0 is considered neutral. The concepts automatically extracted have been: Slovenia; Fonda Fish; \#myway; Instagram; Discover Slovenia; Tourism Council. The concepts we added to the previous to proceed with the sentiment evaluation were \#feelsLOVEnia and @FeelSlovenia. A further step in our Sentiment Analysis algorithm consisted of extracting topics. The result is shown in the following Figure 1.

Figure 1: The detected concepts and related topics, with the correspondent sentiment evaluation

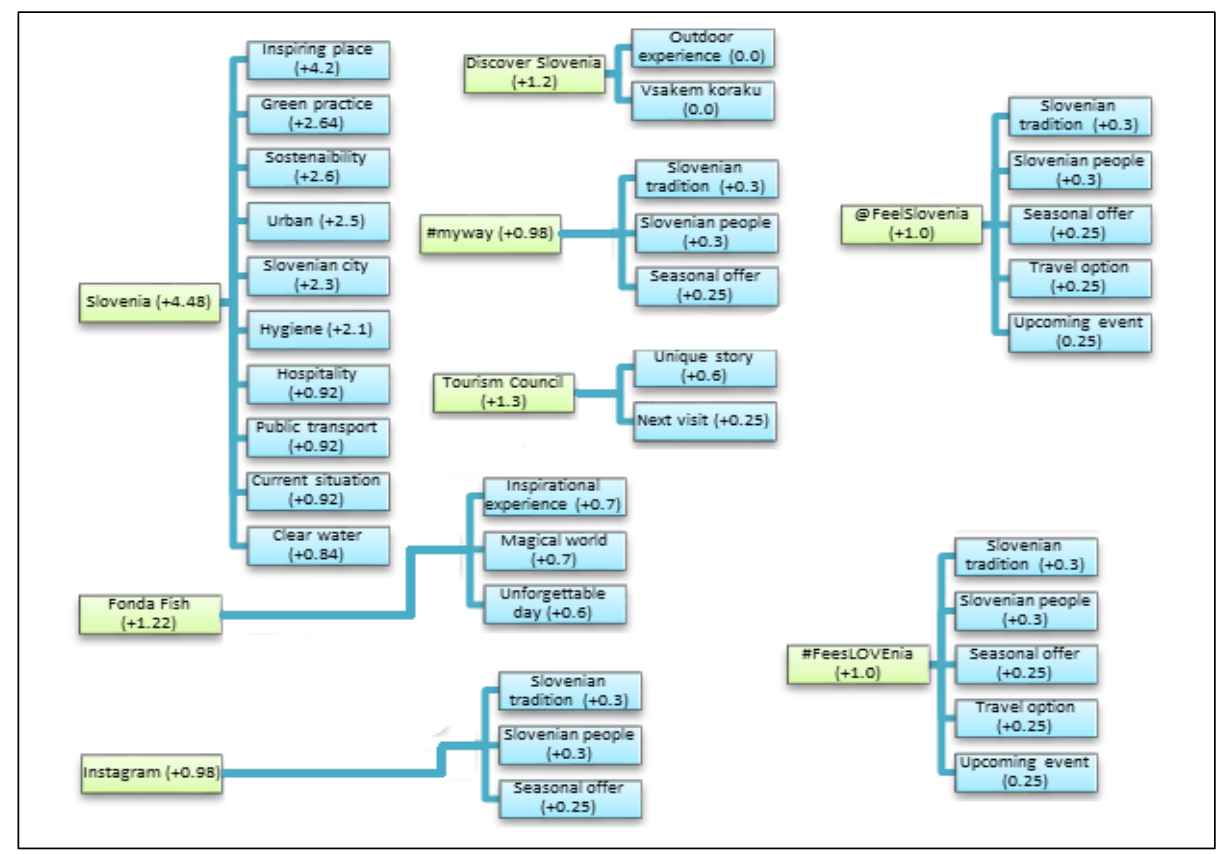


ToSEE - Tourism in Southern and Eastern Europe, Vol. 6, pp. 269-281, 2021.

R. Folgieri, T. Baldigara, S. Gricar: DESIGN OF A WORKBENCH AND GUIDELINES TO IMPROVE ...

Topics correspond to keywords or key sentences showing positive or negative patterns. Topics occurrence has been numbered within each previously detected concept.

In the following table 2, the detected concepts and related topics are depicted, with the correspondent sentiment evaluation. Only positive valuated concepts and topics were considered.

Table 2: The detected concepts and related topics, with the correspondent sentiment evaluation

\begin{tabular}{|c|c|}
\hline Concepts & Related Topics \\
\hline Slovenia $(+4.48)$ & $\begin{array}{l}\text { Inspiring place }(+4.2) \\
\text { Green practice }(+2.64) \\
\text { Sustenaibility }(+2.6) \\
\text { Urban }(+2.5) \\
\text { Slovenian city }(+2.3) \\
\text { Hygiene }(+2.1) \\
\text { Hospitality }(+0.92) \\
\text { Public transport }(+0.92) \\
\text { Current situation }(+0.92) \\
\text { Clear water }(+0.84)\end{array}$ \\
\hline Fonda Fish $(+1.22)$ & $\begin{array}{l}\text { Inspirational experience }(+0.7) \\
\text { Magical world }(+0.7) \\
\text { Unforgettable day }(+0.6)\end{array}$ \\
\hline \#myway (+0.98) & $\begin{array}{l}\text { Slovenian tradition }(+0.3) \\
\text { Slovenian people }(+0.3) \\
\text { Seasonal offer }(+0.25)\end{array}$ \\
\hline Instagram (+0.98) & $\begin{array}{l}\text { Slovenian tradition }(+0.3) \\
\text { Slovenian people }(+0.3) \\
\text { Seasonal offer }(+0.25)\end{array}$ \\
\hline Discover Slovenia $(+1.2)$ & $\begin{array}{l}\text { Outdoor experience }(0.0) \\
\text { Vsakem koraku }(0.0)\end{array}$ \\
\hline Tourism Council (+1.3) & $\begin{array}{l}\text { Unique story }(+0.6) \\
\text { Next visit }(+0.25)\end{array}$ \\
\hline \#FeelsLOVEnia $(+1.0)$ & $\begin{array}{l}\text { Slovenian tradition }(+0.3) \\
\text { Slovenian people }(+0.3) \\
\text { Seasonal offer }(+0.25) \\
\text { Travel option }(+0.25) \\
\text { Upcoming event }(+0.25)\end{array}$ \\
\hline @FeelSlovenia (+1.0) & $\begin{array}{l}\text { Slovenian tradition }(+0.3) \\
\text { Slovenian people }(+0.3) \\
\text { Seasonal offer }(+0.25) \\
\text { Travel option }(+0.25) \\
\text { Upcoming event }(+0.25)\end{array}$ \\
\hline
\end{tabular}

According to previous research results (Folgieri et al. 2018), Sentiment Analysis tools were used to evaluate the perception of the selected website on Social Networks, to investigate whether the impact was significant and still positive.

The general sentiment elicited by the website on social media resulted neutral, indicating that the general tone of the text needs some improvement.The most recurrent words were: 
ToSEE - Tourism in Southern and Eastern Europe, Vol. 6, pp. 269-281, 2021.

R. Folgieri, T. Baldigara, S. Gricar: DESIGN OF A WORKBENCH AND GUIDELINES TO IMPROVE ...

national, Slovenia, park, showing that the handles and the tags have not been echoed by visitors of the website. No mention of the website has been detected on blogs, microblogs, or bookmarks.

The outcome of the analysis phase and the previous checklist allows individuating specific actions to improve the general mood of the content and make it more positive, to contrast the impact of the Covid-19 pandemic on tourism. In fact, at this stage, the content providers should review the content in light of the previous steps.

The final test phase will be performed repeating the previous tasks, filling again the checklist, asking a review to the panel of users, and running again the Sentiment analysis to check if, effectively, the general sentiment of the website results more positive.

\section{CONCLUSION}

The language used and emotions elicited in tourism advertising messages have a strong impact on attracting visitors and tourists, particularly when international events create concerns in the population. Indeed, a multimodal approach, supported by tools from Econometrics, Machine Learning, and Sentiment Analysis showed the efficacy in capturing the mood and the trend in prospect visitors to allow to redistribute tourist flows towards different destinations and within wider periods of the year. Our proposal represents a first novel attempt to design a systematic approach to advertising campaigns setup in tourism, based on a multimodal model matching the creative and the scientific sides of the process. This work descends from our previous studies, allowing us to identify the right tools, guidelines and tests to guide content providers in this process.

The presented model represents the theoretical framework and the guidelines based on our research. Further steps of our research will consist in developing the model, proposing specifically developed tools and apps from Econometrics and Machine Learning, which will constitute the workbench of the proposed framework. Part of these further steps will consist in the development of a virtual assistant specifically designed as an adaptive platform oriented to meet the tourism requirements.

Our final aim is to provide a complete set of tools allowing predictions and mitigation indications in the case of unexpected events. Thanks to a defined approach supported by technological tools based on Inferential Statistics, Econometrics and Machine Learning, the multimodal approach also suggests how maximizing Linguistics hints to improve the efficiency of messages. Last but not least, the proposed model could be used to select the main topics arising on the web and social networks around current issues perceived by visitors, also guiding the selection of a list of Q\&A practical indications which can be translated into effective virtual assistants particularly useful when the personnel is reduced due to unexpected events and constraints, as during Covid-19 periods. 
ToSEE - Tourism in Southern and Eastern Europe, Vol. 6, pp. 269-281, 2021.

R. Folgieri, T. Baldigara, S. Gricar: DESIGN OF A WORKBENCH AND GUIDELINES TO IMPROVE ...

\section{ACKNOWLEDGEMENTS}

This paper has been financially supported by the University of Rijeka, for the project ZP UNIRI 4/18

This research was funded by the Department of Philosophy "Piero Martinetti" of the University of Milan under the Project "Departments of Excellence 2018-2022" awarded by the Ministry of Education, University and Research (MIUR).

\section{REFERENCES}

Cinelli, M., Quattrociocchi, W., Galeazzi, A., Valensise, C. M., Brugnoli, E., Schmidt, A. L., Zola, P. et. al (2020), "The covid-19 social media infodemic", Scientific Reports, Vol. 10, No. 1, pp. 1-10. https://doi.org/10.1038/s41598-020-73510-5

Depoux, A., Martin, S., Karafillakis, E., Preet, R., Wilder-Smith, A. and Larson, H. (2020), "The pandemic of social media panic travels faster than the COVID-19 outbreak", Journal of travel medicine, Vol. 27, No. 3. https://doi.org/10.1093/jtm/taaa031

Flores-Ruiz, D., Elizondo-Salto, A. and Barroso-González, M.D.L.O. (2021), "Using Social Media in Tourist Sentiment Analysis: A Case Study of Andalusia during the Covid-19 Pandemic", Sustainability, Vol. 13, No. 7, 3836. https://doi.org/10.3390/su13073836

Folgieri, R., Baldigara, T. and Mamula, M. (2017), "Artificial neural networks-based econometric models for tourism demand forecasting", Tourism in South East Europe, Vol. 4, pp. 169-182.

Folgieri, R., Baldigara, T. and Mamula, M. (2018), "Sentiment analysis and artificial neural networks-based econometric models for tourism demand forecasting", In Faculty of Tourism and Hospitality Management in Opatija, Biennial International Congress, Tourism \& Hospitality Industry, University of Rijeka, Faculty of Tourism \& Hospitality Management, pp. 88-97.

Folgieri, R. and Bait, M. (2014), "The new profile of the virtual tourist-traveler: communicative perspectives and technological challenges", in Faculty of Tourism and Hospitality Management in Opatija. Biennial International Congress, Tourism \& Hospitality Industry, University of Rijeka, Faculty of Tourism \& Hospitality Management, pp. 408-420.

Folgieri, R., Bait, M. and Carrion, J.P.M. (2016), “A cognitive linguistic and sentiment analysis of blogs: Monterosso 2011 flooding”, In Tourism and Culture in the Age of Innovation, Springer, Cham, pp. 499-522.

Gričar, S. (2019), "Turist kot pacient [Tourists as patients]”, In Kregar-Velikonja, N. and Leskovic, L. (Eds.), Celostna obravnava pacienta: zbornik prispevkov: mednarodna znanstvena konferenca [Holistic approach to the patient: (conference proceedings): international scientific conference], University of Novo mesto, Faculty of Health Sciences, pp. 137-145. Retrieved from https://fzv.uninm.si/uploads/_custom/03_unmfzv/konferenca/zbornik/zbornik_prispevkov_unmfzv_konferenca_ 2019_www.pdf

MacSween, S. and Canziani, B. (2021), 'Travel booking intentions and information searching during COVID19", International Hospitality Review, Vol. 35, No. 2, pp. 208-224. https://doi.org/10.1108/IHR08-2020-0046

Mamula, M., Folgieri, R. and Duvnjak, K. (2019), "SOME CONSIDERATIONS ABOUT ARTIFICIAL NEURAL NETWORKS IN HOTEL INDUSTRY: STATE OF THE ART AND FUTURE DEVELOPMENTS", ToSEE - Tourism in South East Europe, Vol. 5, pp. 431-440. doi: $10.20867 /$ tosee. 05.8

McCabe, S. (2010), Marketing communications in tourism and hospitality, Routledge.

Hamouda, M. (2018), “Understanding social media advertising effect on consumers' responses: An empirical investigation of tourism advertising on Facebook", Journal of Enterprise Information Management Vol. 31, No. 3, pp. 426-445. https://doi.org/10.1108/JEIM-07-2017-0101

Williams, N.L., Wassler, P. and Ferdinand, N. (2020), "Tourism and the COVID-(mis) Infodemic", Letter to the Editor, Journal of Travel Research, Vol. 61, No. 1, pp. 214-218. https://doi.org/10.1177/0047287520981135

Wu, S.I., Wei, P.L. and Chen, J.H. (2008), "Influential factors and relational structure of Internet banner advertising in the tourism industry", Tourism Management, Vol 29, No. 2, pp. 221-236. https://doi.org/10.1016/j.tourman.2007.03.020 
ToSEE - Tourism in Southern and Eastern Europe, Vol. 6, pp. 269-281, 2021.

R. Folgieri, T. Baldigara, S. Gricar: DESIGN OF A WORKBENCH AND GUIDELINES TO IMPROVE ...

Yu, M., Li, Z., Yu, Z., He, J. and Zhou, J. (2020), "Communication related health crisis on social media: a case of COVID-19 outbreak", Current issues in tourism, Vol. 24, No. 19, pp. 2699-2705. https://doi.org/10.1080/13683500.2020.1752632

Raffaella Folgieri, PhD, Assistant Professor

Università degli Studi di Milano,

Department of Philosophy

Via Festa del Perdono 7, Milan, Italy

+390250312739

Raffaella.Folgieri@unimi.it

Tea Baldigara, $\mathrm{PhD}$, Full Professor

University of Rijeka, Faculty of Tourism and Hospitality Management

Department for Quantitative Economy

Primorska 42, 51410 Opatija, Croatia

+38551294684

teab@fthm.hr

Sergej Gricar, PhD, Assistant Professor

University of Novo mesto, Faculty of Business and Management

Na Loko 2, 8000 Novo mesto

+38673930026

sergej.gricar@uni-nm.si 